\title{
COVID-19 and the Creative Music Ecology
}

\section{Karen Ng and Scott Thomson}

As the Artistic Direction of the Guelph Jazz Festival, our complementary strengths derive from our diverse connections within the local, national, and international fields of creative improvised music. We hear ourselves foremost as improvising musicians, which comprises a range of related activities, including collective improvisation, interpretation, and composition in various registers and modes. These activities reside within networks that are private or public to different degrees and in various ways, including practice, rehearsal, less-formal performance (bars, studio spaces), more-formal performance (theatres, festivals), touring, recording, curating, broadcasting, teaching, writing, etc. Every aspect of this network has its discrete function and contributes to the field as a whole, thereby forming an ecology of interrelated conditions and contexts that contribute to the overall health and vibrancy of the field. This ecology is manifested differently in various cities and regions, responding to the priorities of its artists as well as financial and other contingencies of a discrete locale.

Scott has been based in Montreal for a decade but has an extensive history in Toronto, where Karen is based. She has also made significant inroads in New York, Amsterdam, Berlin, and Vancouver, for example, extending from her curatorial work with Toronto's Tone Festival and Somewhere There, which Scott founded in 2007 as an outcropping of his work with the Association of Improvising Musicians Toronto (AIMToronto) and the AIMToronto Orchestra. As artists and producers, we have engaged with recording projects and labels in Toronto (Barnyard Records, All Set! Editions), Montreal (Ambiances Magnétiques, Small Scale Music), elsewhere in Canada (Spool, Uxbridge, ON; Tour de Bras, Rimouski, QC; Bug Incision, Calgary, AB), and internationally (Nessa Records, Buffalo, NY).

The sum of these experiences is that, in a typical period, we are splitting time between our own creative projects (practice, rehearsal, performance, recording, touring), contributing to those of our peers (rehearsal, performance, recording, touring), and administering various curatorial projects, the Guelph Jazz Festival chiefly among them. Key to these activities, of course, is the ability to gather with others-collaborators and audiences-within the different contexts the field comprises. The impact of COVID-19 on the field starts, but by no means ends, by restricting these gatherings. This essay explores how pressures the virus places on aspects of creative music ecology threaten its very nature. Moreover, it hints at how creative music, despite its marginal role in the music industry and public discourses more generally, embodies vital, if intangible, components of our humanity, those that are laid bare by our inability to engage them during a pandemic.

\section{Shifting Terrain}

Clearly the pandemic has had a devastating impact on all performing arts, including the virtual elimination of live music presentation, the cancellation of series and festivals, and the closure of venues. Along with the Guelph Jazz Festival Board of Directors, we had little difficulty in May 2020 cancelling the September festival in favour of alternate programming. In our decision, we faced two key questions: 1) Would Public Health allow us to present a festival? and 2) Even if we could do so, would our audience be ready to attend live music events in September? The answer to the first was impossible to predict accurately in May, but the answer to the second seemed then-and only seems more so as we write this article in the summer of 2020 - to be an unequivocal "no." We feel strongly that there is an enormous, surely growing, appetite for live 
music, but as more is known about COVID-19, particularly in the wake of premature re-openings in the United States, the groundswell of caution afoot says that promoting large gatherings in September would be a bad and possibly reckless idea.

In a few short months, public attitudes have been justifiably transformed, and while many sectors of the economy have reopened in adaptive ways and the public is slowly re-emerging into many kinds of public space, it is apparent that live music events may be some of the last to be sanctioned officially and accepted culturally. Even at a point where there is official approval to present live music, the next steps will be necessarily experimental. Some presenter will have to be the first, and will thus face a new set of risks, the biggest of which is likely financial, in a context where audiences will surely be wary. The presentation models will have to change, and physical distancing protocols will attack presenters' - and thereby musicians' - capacity to earn revenue. Clearly, until there is a widespread, effective, affordable COVID-19 vaccine, the economics of live music will need to be re-envisioned and transformed. It is not obvious that adaptations will forge a sustainable model.

Amid this uncertainty, presenters, venue managers, and musicians have tried to imagine live music as it will become possible, while fighting the despair that falls out from the decimation of our field. Many presenters have opted to livestream concerts as a way to offer programming of some sort, and independent musicians have likewise livestreamed concerts as a way to generate revenue, engage in some kind of performance practice, and connect with audiences. While Karen has done a livestream performance as an independent musician, to date we have not offered livestreams as presenters, particularly under Guelph Jazz Festival auspices.

\section{Livestreaming and the Flattening of the Field}

Like most musical (and other artistic) fields, creative improvised music functions in a range of contexts, registers, and spaces (both physical and recorded), comprising interdependent activities that many or most members of the field engage: practice, rehearsal, performance (in many contexts in different degrees of formality), touring, recording, promotion, curatorial work, and more. Our own typical professional activities as described above are cases in point.

In a pandemic context, a livestreamed concert, at first blush, would seem to replace otherwiseunfeasible live performances within this ecosystem, serving to "gather" listeners remotely for some kind of shared experience. Modeled on the concert experience, they strive to give "attendees" direct access to an artist presenting new work in real time, offering listeners a sense of exclusivity and shared experience.

There are of course practical reasons why livestream concerts proliferate during the pandemic. Artists seek to connect with audiences in order to make some money, to promote their recordings, and to retain a presence in the field during a time when concerts, tours, and festivals have all been cancelled or postponed. We would never suggest that artists should not livestream their work, and naturally we support their endeavours to share music and make a living as best they can. However, both as audience members and (in Karen's case) a performer of livestream concerts, we question what they actually achieve.

While livestream concerts strive to replace concerts in the current situation, they more readily contribute, formally, to the recorded segment of the creative music ecosystem generally, and the video streaming sub-segment of it more specifically. Like most of our peers, over the years we have spent considerable time-likely far too much time! — checking out YouTube videos of improvising musicians at work both near and far. This experience, in MP3 sound quality and 
often shaky, archival-quality AN recording (much of it from mobile phones), is good for research but scarcely reproduces the audio richness, let alone the ambiance, of a live concert context.

During the pandemic, many musicians and presenters have sought to present livestream concerts in higher-quality formats. However, the mediation and attendant barriers of shaky internet signals, computer speakers of variable quality, near-inevitable technical glitches, a lack of skilled sound technicians to capture the musician's sound, etc. rob the music of its presence, a quality that musicians work tirelessly to be able to project into a live concert space, and which recording, mixing, and mastering engineers work tirelessly to document on record.

As a result, the livestream concert falls in between discrete and vital elements of the ecosystem that makes the field of creative music vibrant. It's not really a concert and it's not really a recording, and its in-between status makes it less than either. Granted, without any other real options for real-time performance, it's the best we have for the moment. However, we would argue that livestream concerts may actually detract from the field by reducing performance to a formal gesture that ignores some of the vital-if intangible-qualities that are obtained when we gather in the same room to play and hear music.

Perhaps it's better to consider livestreaming as a separate medium, without bestowing upon it the pressure of replacing live performance. Thus considered, it could carve out its own role in the creative music ecosystem, just as different media have become integrated into, and thereby thoroughly influenced, recorded jazz throughout its history. For instance, many contemporary performances feature integral visual elements, and their creative deployment can make the A/V experience very satisfying. However, with a trove of pre-recorded performances (both professionally and on phones) already accessible on the internet, we question whether the realtime aspect of livestream performances serves any real function, other than to enable the chat function that can at once be funny and distracting.

Karen's livestream experience accords with what we've heard, anecdotally, from numerous colleagues: Pandemic livestream concerts are strange, lonely experiences that force most improvising musicians to work solo, a highly specialised context that does not suit them all. They offer a compromised context for work that, arguably, is only really animated through the interactions of people: musician and musician, and musician(s) and audience. While some may say that this is a condition of virtually all music, we believe it is particularly acute in the field in which we work. And by making these connections so thoroughly diffuse through mediation, it robs the music of something essential.

In Scott's formulation, creative music is understood not in contradistinction to uncreative music (which he does not think exists), but to re-creative music, where performance details are sorted out largely or wholly in advance. Creative music proposes contexts (typically composition in different degrees and registers) where some or all of those details are determined in performance, and the relationships between these actors (musicians as well as audience members) contribute tangibly to this process.

With this in mind, in a livestream context where these relationships are so thoroughly mediated, we wonder to what degree a performance of ostensible improvisations is "creative music" at all. Those relationships, in an unmediated context and manifested in sounds that people enjoy or by which they are provoked, may well be what the music is about. The more we experience a situation in which the immediate/unmediated is, for now, unfeasible, the more we are reminded that the relationships creative music makes possible are a principal reason we're involved in the field in the first place. 


\section{The Medium and the Channelling of Specialty}

We are lucky to work in a field that is teeming with creativity and ideas, and some of those ideas are well expressed in a livestream context. Inevitably, this condition has changed the focus of some musicians, who are spending more time on work that can be effectively livestreamed, perhaps at the expense of other aspects of their practice that cannot. A musician who jointly focusses on acoustic group music as well as solo computer music would understandably make the latter a priority in 2020.

Interesting projects have emerged from this period of isolation, including recording concepts for improvisers. A large-scale project organised by Vancouver's NOW Society assembled thirty improvisers and two engineers to make recordings of various durations and musical combinations. Musicians recorded themselves before sending it to the next player to add another layer and so on until it was "completed." The pieces had predetermined durations and the process of layering mitigated the issue of latency, an inevitable factor when improvising in real time through applications like Zoom. Musicians were to interact with the material they were sent and were not privy to how the full track sounded until it was done. Each player could start, finish, or contribute in the middle of the piece, determined by a weekly schedule. This process encouraged players to consider recording not only as a means of documentation, but also as a creative space, to be approached more as a deliberate composition than as a purely interactive endeavour.

While this concept, to which Karen contributed, was satisfying to participate in and hear, it explores a certain aspect of recording and composing without replacing the function of improvising together in the same time and place. It offers an alternative to collaborative music with the act of improvising intact, but without the element of real-time interaction. To Karen, it was clear from the outset that the approach would differ from how one might consider playing in a live setting. By comparison, her solo, improvised livestream experience faltered because she approached it with the same mindset as she would a live set. As a result, it felt two-dimensional, a shadow of something about which we care very much, an experience robbed of meaning by being presented in the wrong context (much like playing music in the wrong live venue, while the audience is chatting and eating, for example).

With these reservations in mind, we, like many creative musicians, are faced with a current condition in which a principal component of our work makes seemingly little sense. We both play wind instruments that demand considerable work in order to remain in playing shape. With the pandemic preventing the kinds of gatherings that are emblematic of so much of the "typical" creative music ecosystem in which we work, it is hard to be motivated to stay in shape, let alone develop new music in a context where it cannot be shared and heard optimally.

This provokes broader questions about what it means to practice, echoing a recent conversation between Jeremiah Cymerman and trumpeter Peter Evans through Cymerman's 5049 Podcast ("Coronocast \#7"): Under typical circumstances, many of us practice specifically for upcoming projects or concerts. Evans welcomes the reintroduction of the idea of the "practice of practice," to work on a concept and play with it out of curiosity and discovery, not just for professional preparation or maintenance. It is a state of mind that can be difficult to access; much like meditation, it can surely yield a different sort of satisfaction than one based on an end result. Still, in practice, we find it hard to practice these days.

Unlike many of our colleagues, we have in fact devoted a lot of attention to solo playing, which at first glance would seem to make pandemic-era livestream presentation more appealing. 
However, we have both worked hard to release solo recordings (Scott has two and Karen has one) and, given what we've said above about the unsatisfyingly in-between nature of livestream concerts, we would rather share these recordings, which more directly speak to our artistic goals. Ultimately, in the face of compromising media, we agree that just because we can, it doesn't mean we should share our music these days. What we do is specific, special, and not to be given away so easily, projected into the abyss of the internet where its meanings are lost or, at best, uncertain.

The result is that, like so many of our peers, we are thrust into a position where we don't really want to present our music in the compromised circumstances. Meanwhile, some musicians have embraced the livestream model, through which they can channel one of their musical specialities (or indeed are transforming their practice) to work more comfortably within the medium. We are curious to know what impact this channelling of creative music activity will have on the field, longer-term. The richness of the ecosystem is currently threatened and, while we have faith in musicians' creativity and resilience, we wonder if and how it may be permanently altered due the influences of the pandemic such as these.

Add to this the closure of venues that have supported creative music — La Vitrola in Montreal, for example-and it is clear that the physical infrastructure on which the field is based is also under severe stress. There is no question that, post-pandemic, this altered landscape will reshape what and limit how much music gets made and presented.

\section{In Search of Festive Music}

Unlike many festivals in Canada and elsewhere, to date we have opted not to present any livestreamed programming during the pandemic under Guelph Jazz Festival auspices. While we laud our colleagues who have sought to present and support artists during this period, we keep facing a fundamental responsibility. It's not one that is inscribed in our mandate or mission statement, but in our very name. As of now, we cannot conceive of online programming that feels festive, and to us it seems like a disservice to the organisation and to the field in general to offer anything less.

Thinking through this responsibility, we take to heart our interwoven relationships throughout the aforementioned ecosystem of creative music. Festivals serve an important, but ultimately rather secondary, role in the incubation and development of creative music. While we are proud to present, apart from in 2020, an annual program of outstanding music reflecting the stylistic, geographical, and demographic breadth of the creative music field, we are able in the end to present merely a small segment of the incredible work being done locally, regionally, nationally, and internationally. As such the work is by no means representative of the teeming creativity afoot.

Instead, the feeling of festivity that we seek is, at root, based on the relationships-musicians with musicians, musicians with audiences - that animate the music itself. More than many kinds of music, we would argue, creative music is engaging because listeners can feel something being made right in front of them, perhaps even feeling their own influence on the process. A creative music festival is a series of such experiences, animating different spaces with different musics in hopefully complementary or usefully contrasting ways that make compound such engagement. The joy of the experience, we hope, is not only a sequence of enjoyable or provocative sounds, but more thoroughly the multiplying feeling of manifest creativity that artists and audiences enact together. 
Naturally, these days we yearn for such experiences as performers, curators, and listeners. Life feels pretty two-dimensional without them. In the meanwhile, we will keep considering ways that music can be presented in safe and engaging ways that do not involve streaming or related internet mediation. While the motivation for such a project may simply boil down to our particular priorities as curators and artists, it may also point to what is truly vital not only in the field of creative music but also, and simply, in life in general: Sharing joyful and inspiring experiences with others in the same time and place helps to make life worth living. 